\title{
Modified lattice parameter/Curie temperature diagrams for titanomagnetite/titanomaghemite within the quadrilateral $\mathrm{Fe3O}_{4}$ - $\mathrm{Fe}_{2} \mathrm{TiO}_{4}-\mathrm{Fe}_{2} \mathrm{O}_{3}-\mathrm{Fe}_{2} \mathrm{TiO}_{5}$
}

\author{
Weixin Xu, Donald R. Peacor, and Rob Van der Voo \\ Department of Geological Sciences, The University of Michigan, Ann Arbor, MI
}

Wayne Dollase

Department of Earth and Space Sciences, UCLA, Los Angeles, CA

Rick Beaubouef ${ }^{1}$

Department of Geosciences, University of Houston, Houston, TX

\begin{abstract}
Magnetic and mineralogical data were obtained on a sequence of titanomagnetite - titanomaghemite solid solutions from four basalt samples $(0$ to $70 \mathrm{Ma})$ dredged from four sites along a traverse normal to the mid-Atlantic Ridge. Data which characterized magnetic iron oxides with the spinel structure include Mössbauer, XRD (including Rietveld structure refinement), TEM/AEM, and magnetic data. The data indicate a sequence ranging from nearly unoxidized titanomagnetite to near end-member titanomaghemite. Compositions of samples with intermediate values of oxidation parameter, $Z$, varied significantly from those estimated using previously determined relations between lattice parameters and compositions. The data of this study, in conjunction with those of selected references, lead to more accurate contoured diagrams for Curie temperature and lattice parameter (as consistent with Vegard's law) for the quadrilateral $\mathrm{Fe}_{3} \mathrm{O}_{4}$ $\mathrm{Fe}_{2} \mathrm{TiO}_{4}-\mathrm{Fe}_{2} \mathrm{O}_{3}-\mathrm{Fe}_{2} \mathrm{TiO}_{5}$.
\end{abstract}

\section{Introduction}

The major primary magnetic mineral in ocean floor basalts is titanomagnetite, which undergoes progressive maghemitization during low-temperature alteration. Members of the magnetite - titanomagnetite series plot along the join $\mathrm{Fe}_{2} \mathrm{TiO}_{4}-\mathrm{Fe}_{3} \mathrm{O}_{4}$ in the ternary diagram $\mathrm{FeO}-\mathrm{Fe}_{2} \mathrm{O}_{3}-\mathrm{TiO}_{2}$ (Figure 1). The two sets of horizontal or nearly horizontal contours extending to the right of that join correspond to trends for progressive oxidation, the dashed contours corresponding to addition of oxygen, and the solid contours to loss of iron [Petersen et al., 1979; Ryall and Hall, 1980; O'Reilly, 1983]. The reaction corresponding to loss of iron, as is the case for the samples described below, may be summarized as:

$$
\begin{aligned}
\mathrm{Fe}_{3-\mathrm{X}} \mathrm{Ti}_{\mathrm{X}} \mathrm{O}_{4} \rightarrow & (1-\mathrm{Z})\left(\mathrm{Fe}_{3-\mathrm{X}} \mathrm{Ti}_{\mathrm{X}} \mathrm{O}_{4}\right) \\
& \cdot \mathrm{Z}\left(\mathrm{Fe}_{(8-4 \mathrm{X}) / 3} \square_{(1+\mathrm{X}) / 3} \mathrm{Ti}_{\mathrm{X}} \mathrm{O}_{4}\right)+\mathrm{Fe}_{(\mathrm{Z} / 3)(1+\mathrm{X})}
\end{aligned}
$$

where $\mathrm{Z}(0 \leq \mathrm{Z} \leq 1)$ is the oxidation parameter (the fraction of titanomaghemite), $X(0 \leq X \leq 1)$ is the original ulvöspinel component, and $\square$ denotes vacancies.

Many investigators have attempted to establish functions among cell dimension (A, the cubic subcell translation), Curie

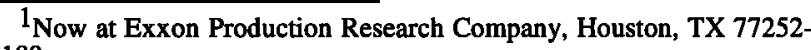
2189
}

Copyright 1996 by the American Geophysical Union.

Paper number 96GL01117

0094-8534/96/96GL-01117\$05.00 temperature $\left(\mathrm{T}_{\mathrm{c}}\right)$, and $\mathrm{Z}$ [e.g., Akimoto et al., 1957; Ozima and Sakamoto, 1971; Readman and O'Reilly, 1972; Keefer and Shive, 1981; Nishitani and Kono, 1983]. However, significant differences exist between those of different authors [Moskowitz, 1987]. The inconsistencies among available contour diagrams imply that there are large errors in values so determined [Moskowitz, 1987]. The cause of inconsistencies therefore likely lies in poorly defined and correlated parameters such as cell dimensions, titanium contents, and most importantly, degrees of oxidation.

In addition, the process by which maghemitization takes place in nature may be very different than that for synthetic materials, whereas previously published contour diagrams are based on studies of synthetic materials [Moskowitz, 1987]. In nature, the process involves loss of iron and production of vacancies, independent ordering of vacancies, retention of $\mathrm{Ti}$, and retention of the coherency of primary crystals [Xu, 1996]. Although there are very limited data for natural titanomaghemite the published data show even more disagreement concerning the relationship between $\mathrm{A}$ and $\mathrm{Z}$, when data for synthetic material and natural material are compared [e.g., Ozima et al., 1974].

Because titanomagnetite-titanomaghemite occurring in MORB is so fine-grained, the oxidation state can generally not be determined accurately, in part because of contamination by associated minerals. The Rietveld method is a technique

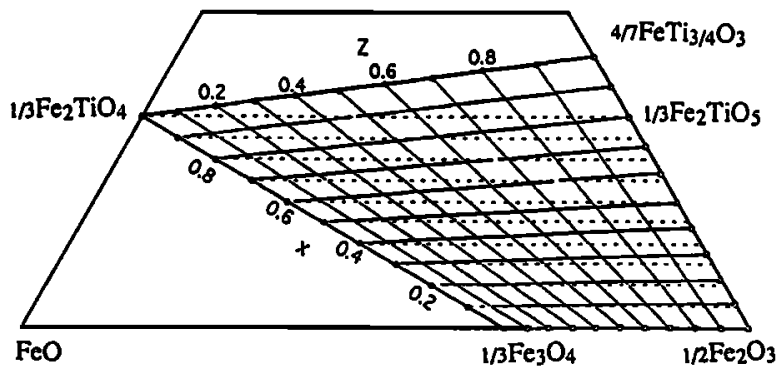

Figure 1. Lower part of the $\mathrm{TiO}_{2}-\mathrm{FeO}-\mathrm{Fe}_{2} \mathrm{O}_{3}$ ternary diagram showing the chemical composition field of titanomagnetite/titanomaghemite within the $\mathrm{Fe}_{2} \mathrm{TiO}_{4}$ $\mathrm{Fe}_{2} \mathrm{TiO}_{5}-\mathrm{FeO}-\mathrm{Fe}_{2} \mathrm{O}_{3}$ quadrilateral. Compositions of primary magnetic minerals lie along the join $\mathrm{Fe}_{2} \mathrm{TiO}_{4}-\mathrm{Fe}_{3} \mathrm{O}_{4}$. Slightly inclined, solid contours extending to the right correspond to oxidation by loss of $\mathrm{Fe}$, whereas horizontal dashed contours correspond to oxidation by addition of oxygen (Modified from O'Reilly, 1983). Contours corresponding to constant $\mathrm{Z}$ are also shown. 
with utilizes powder diffraction data for refinement of crystal structure parameters, including as in the case of magnetite the fractional occupancy of the cation sites. Such data may even include contributions from contaminating phases, and is especially powerful when augmented by less definitive data from other methods such as Mössbauer analysis.

Based on detailed characterization of a sequence of natural samples ranging from nearly unaltered titanomagnetite to nearly fully oxidized titanomaghemite [Xu 1996], we have directly correlated magnetic parameters, composition, and crystal structure parameters. In this paper we show how those data lead to improved contour diagrams for lattice parameters and Curie temperatures.

\section{Sample descriptions and summary of properties}

A detailed description of mineralogical and magnetic data is given by $\mathrm{Xu}$ [1996], so only a brief review is provided here, with properties summarized in Table 1.

The samples used in this study were collected at four sites from the Atlantic Ocean at varying distances from the midAtlantic Ridge [Beaubouef, 1993]. With increasing distance from the ridge, the ages for sites 1 through 4 are $<1,9,26$, and $70 \mathrm{Ma}$, respectively. All samples consisted of pillows with thin glassy rims and crystalline interiors.

Based on optical and electron microscopic observations, the dominant opaque mineral in all samples is euhedral titanomagnetite or titanomaghemite, commonly with dendritic and cruciform shapes as consistent with quenching of pillows from high temperatures [Somboonsuk and Trivedi, 1985]. Grain sizes as resolved by back scattered electron imaging are dominantly in the range of 1 to $10 \mu \mathrm{m}$ [Xu, 1996].

Data from a number of sources (transmission and analytical electron microscopy (TEM/AEM), electron microprobe analysis (EMPA), Mössbauer spectroscopy, oxygen isotope analysis, and powder X-ray diffraction (Rietveld refinement of lattice and crystal structure parameters) [Post and Bish, 1989]), showed that titanomagnetite from site 1 is nearly or completely unaltered titanomagnetite, whereas that from site 4 is nearly completely oxidized and vacancy-ordered titanomaghemite. All material is of similar size and shape, and sceptar to skeletal-shaped grains are single crystals. Material from sites 2 and 3 is of intermediate oxidation states, but vacancies are not ordered. Compositions of individual crystals vary over only small ranges, and the range of composition for any one site is small. The calculated average ulvöspinel component, as determined from Ti/Fe ratios from AEM analyses [Xu, 1996], varies irregularly from $\mathrm{x}=0.58$ to 0.73 independent of distance from the spreading ridge, implying that there has been no significant loss of $\mathrm{Ti}$.

Saturation magnetization curves for heating both in helium and in air were similar for all samples whereas the cooling curves were distinctly different for samples with different ages. For the samples from site 1 , the thermomagnetic curves were

Table $1 Z$ values estimated by different methods

\begin{tabular}{cccccc}
\hline Sample & $x$ & $\mathrm{~A}(\AA)$ & \multicolumn{2}{c}{$\mathrm{Z}$} \\
& & & $\mathrm{a}$ & $\mathrm{b}$ & $\mathrm{c}$ \\
\hline 1 & $0.64 \pm 0.05$ & $8.4664 \pm 0.0005$ & 0.24 & 0.19 & 0.11 \\
2 & $0.74 \pm 0.05$ & $8.4028 \pm 0.0005$ & 0.76 & 0.48 & 0.57 \\
3 & $0.60 \pm 0.05$ & $8.3828 \pm 0.0005$ & 0.82 & 0.56 & 0.68 \\
4 & $0.72 \pm 0.05$ & $8.3607 \pm 0.0005$ & 0.93 & 0.87 & 0.85 \\
\hline
\end{tabular}

a - $Z$ values determined by using Readman and O'Reilly's contour diagrams [1972];

b - $Z$ values determined by refinements of site occupancies; c - $Z$ values determined by refinements of cell dimensions. almost reversible when samples were measured in helium, but non-reversible when measured in air [Xu, 1996]. For samples from other sites, the thermomagnetic curves were nonreversible both in helium and in air, and values of saturation magnetization increased up to three times original values. Some samples contained a small component $(<5 \%)$ with $\mathrm{T}_{\mathrm{c}} \approx$ $500{ }^{\circ} \mathrm{C}$, but in view of the non-reversibility of the curves, it is not possible to conclude whether it is a chemical reaction of magnetic phases at high temperature. All $\mathrm{T}_{\mathrm{c}}$ values were therefore determined based on heating curves in helium for the smaller major $T_{c}$ component. For a single site, measured $T_{c} s$ vary from rim to core in irregular ways but within a small range $\left(< \pm 30^{\circ} \mathrm{C}\right)$. Results showed a regular increase of $\mathrm{T}_{\mathrm{c}}$ from $180 \pm 30^{\circ} \mathrm{C}$ for the youngest samples to $350 \pm 30^{\circ} \mathrm{C}$ for the oldest samples. The samples from sites 2 and 3 have intermediate $T_{c} s$ of $200 \pm 30$ and $300 \pm 30^{\circ} \mathrm{C}$, respectively [Xu, 1996].

\section{Application of parameters to existing contoured diagrams}

Extensive data on the cell parameters of members of the ulvöspinel - magnetite and magnetite - maghemite solid solutions exist in the literature and those data are in approximate agreement [Lindsley, 1976; Waychunas, 1991]. Data for completely oxidized titanomaghemite samples indicate that their lattice parameters are independent of $\mathrm{Ti} / \mathrm{Fe}$ ratio, or nearly so $(A \approx 8.33-8.34 \AA)$. In other words, there is general agreement about the magnitude of lattice parameters for samples with compositions plotting along the left, right, and bottom limiting joins of the $\mathrm{Fe}_{3} \mathrm{O}_{4}-\mathrm{Fe}_{2} \mathrm{TiO}_{4}-\mathrm{Fe}_{2} \mathrm{O}_{3}-$ $\mathrm{Fe}_{2} \mathrm{TiO}_{5}$ quadrilateral. This conclusion is in agreement with results on synthetic samples reported by Readman and O'Reilly [1972], and is consistent with the data of Collyer et al. [1988] and Allan et al. [1989] on natural samples.

The data of this study are also in agreement with those noted above for the limiting tie-lines of the quadrilateral; e.g., the magnetic fraction from a sample from site 1 has $A=8.4664 \pm$ $0.0005 \AA$ which, considering the average ulvöspinel component $(x=0.64 \pm 0.05)$ is consistent with minor oxidation. The $\mathrm{T}_{\mathrm{c}}$ value of $180 \pm 30^{\circ} \mathrm{C}$ corresponds to $\mathrm{Z} \leq$ 0.3 , based on Readman and O'Reilly's [1972] contour diagram. This is in qualitative agreement with our determination of $\mathrm{Z}$ in that this sample is least oxidized. The value, however, is greater than that determined by Rietveld refinement of the site occupancy (Table 1). In addition, the magnetic fraction from a sample from site 4 has $A=8.3607 \pm 0.0005 \AA$, indicating nearly complete oxidation, given that the ulvöspinel component is $x=0.72 \pm 0.05$. The $T_{c}$ value of $350 \pm 30^{\circ} \mathrm{C}$ leads to a value of $Z \approx 0.9$, based on $x=0.7$ and Readman and O'Reilly's [1972] contour diagram. This is again in qualitative agreement with our mineralogical data which imply that oxidation proceeded to $90 \%$ titanomaghemite [Xu, 1996].

On the other hand, our results show that the $Z$ values determined by Rietveld refinement of structures (site occupancy) of the two intermediate samples (Figure 2, open circles for sites 2 and 3 ) are much smaller than those determined from lattice parameters via Readman and O'Reilly's contour diagram [1972] (Figure 2 triangles), although the results for sites 1 and 4 are similar (Figure 2 and Table 1). Because the lattice parameter, $A$, is also a function of $\mathrm{Ti}$ content, observed lattice parameters were adjusted to values consistent with the composition $\mathrm{Uv}_{60} \mathrm{Mt}_{40}$, a composition which is intermediate to those of the four studied samples. The amount of adjustment is very small ( $\Delta \mathrm{A}<0.002 \AA)$. If the data from Nishitani and Kono [1983] were plotted in this diagram, they would also have defined a similar upward-curved line, significantly different from the measured data for sites 2 and 3 


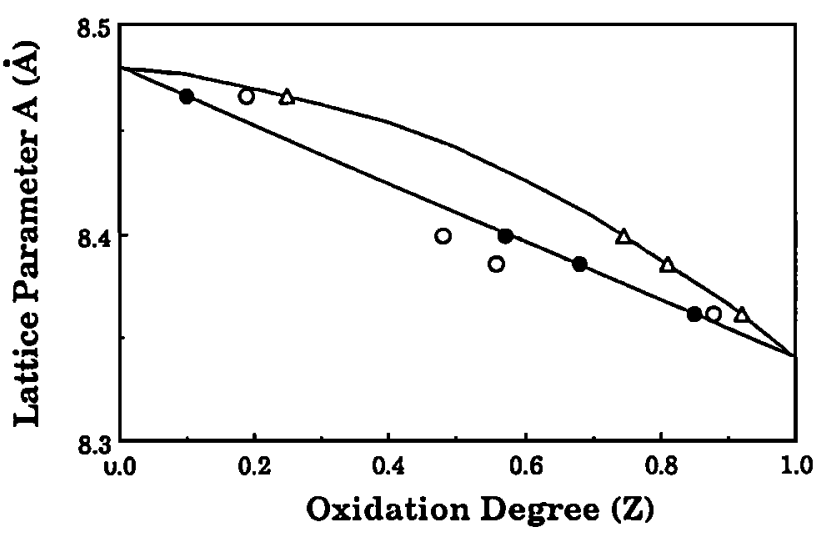

Figure 2. Plot of lattice parameter (A) vs. degree of oxidation ( $Z$ ) for titanomagnetite -titanomaghemite solid solution ( $\mathrm{x}=0.6$ ) determined by: (1) site occupancy refinements (open circles), (2) lattice parameters assuming that $A$ varies linearly with degree of oxidation (filled circles), and (3) lattice parameters based on Readman and O'Reilly's [1972] experimental results (triangles) (see text for details).

and inconsistent with Vegard's law. In other words, the degree of oxidation determined by using those existing contour diagrams is much greater than that determined by linear correlation and $\mathrm{A}$ values, especially for the titanomagnetite with intermediate degree of oxidation.

Discrepancies between values determined through laboratory studies and those for natural samples as determined in this study are significant only for compositions inside the general area of the quadrilateral. This may be due in part to different oxidation mechanisms in the laboratory and in nature. It is therefore necessary to propose a model for the extrapolation of plots of cell dimensions of titanomaghemite into the general area of the quadrilateral for natural samples, assuming general agreement for values on three limiting tielines.

According to Vegard's law, the lattice parameters of solid solution series vary linearly with atomic proportions of endmembers [Hazen and Finger, 1982 and references therein] where solid solutions are thermodynamically ideal. Even for non-ideal solid solution, lattice parameters do not generally depart significantly from linear correlations. Figure 2 shows the plot of A vs. Z from data of Readman and O'Reilly [1972] (triangles), implying a non-linear correlation between $\mathrm{A}$ and Z. In addition, a recent study [Fukasawa et al., 1993] has shown that A actually varies linearly with solid solution in magnetite and maghemite. We therefore assume a linear relation between lattice parameters and solid solution for naturally-occurring titanomagnetite and titanomaghemite. This is further supported by the data of Figure 2 which show that the trend of values determined by Rietveld refinement of site occupancies and lattice parameters approximates a straight line. We have, therefore, constructed an alternative set of contours (Figure 3a) based on a linear relation between $A$ and $Z$, which assumes that the alteration mechanism involves loss of $\mathrm{Fe}$.

Figure $3 \mathrm{a}$ shows the compositions for the four samples, as determined on the basis of $\mathrm{Ti} / \mathrm{Fe}$ ratios measured by AEM and Rietveld refinement of cell dimensions (filled symbols) and as determined on the basis of the $\mathrm{Ti} / \mathrm{Fe}$ ratios and Rietveld refinement of site occupancies (open symbols). Also shown are values for the samples of Collyer et al. [1988] and Allan et al. [1989]. The Z-values as determined on the basis of $A$ values and $\mathrm{Ti} / \mathrm{Fe}$ ratios are in good agreement with those from Rietveld structure refinements.
Our results and those of others [Ryall and Hall, 1982, and references therein] have shown that $Z$ values determined using Readman and O'Reilly's diagrams contoured for $A$ and $T_{c}$, are consistent only on a relative basis. On the other hand, the differences in $T_{c}$ between different laboratories are likely caused by different experimental conditions involving such factors as gas media, oxygen activity, and heating rate. Although the experimental conditions for Readman and O'Reilly's measurements [1972] have not been reported in detail, our measured $T_{c}$ values are consistent with those based on Readman and O'Reilly's functions among $\mathrm{T}_{\mathrm{c}}, \mathrm{A}$, and $\mathrm{Ti}$ content, implying compatibility in those results. We, therefore, constructed a new contour diagram for $\mathrm{T}_{\mathrm{c}}$ (Figure $3 \mathrm{~b}$ ) assuming that Readman and O'Reilly's correlation between $T_{c}$ and $A$ is correct, but using our modified diagram for $A$ vs. $Z$ (Figure 3a). The modification is based on composition relations and therefore is not related to the oxidation mechanism. Contour lines are extrapolated into the upper area that was not included in Readman and O'Reilly's [1972] diagram. This yields a diagram equivalent to that of Readman and O'Reilly, but assuming a linear relation for solid solution parameters.

(a)

$\mathrm{TiO}_{2}$

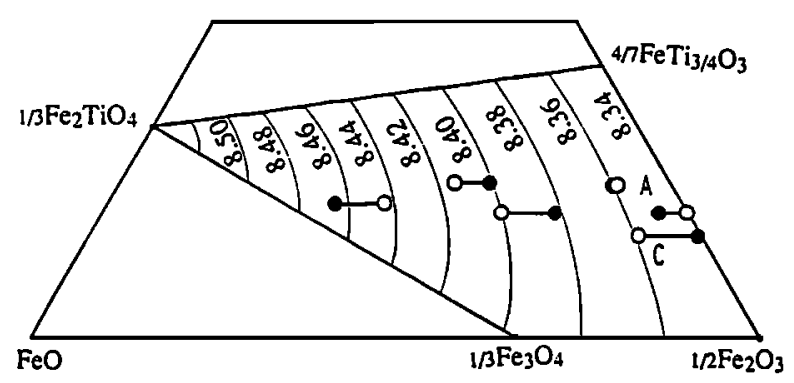

(b)

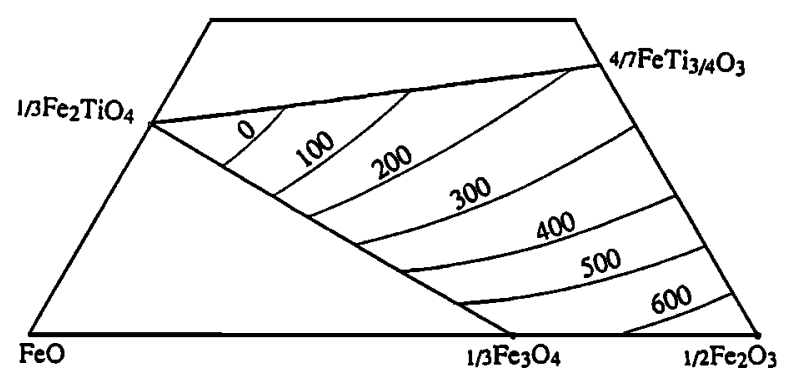

Figure 3 (a) Contours of constant $\mathrm{A}$ in the $\mathrm{TiO}_{2}-\mathrm{FeO}$ $\mathrm{Fe}_{2} \mathrm{O}_{3}$ ternary system based on linear interpolation (Vegard's law) between measured lattice parameters $(\AA)$ of fully unoxidized titanomagnetite and fully oxidized titanomaghemite. Also shown are chemical compositions of the four samples of this study, plotted in the $\mathrm{TiO}_{2}-\mathrm{FeO}$ $\mathrm{Fe}_{2} \mathrm{O}_{3}$ ternary system. Filled circles correspond to compositions inferred from the cell dimensions, and open circles to compositions determined from Rietveld structure refinements. Points $\mathrm{A}$ and $\mathrm{C}$ refer to values reported by Allan et al [1989] and Collyer et al. [1988] respectively. (b) Contours of Curie temperature $\left({ }^{\circ} \mathrm{C}\right)$ based on contours established in Fig. 3a for A, and the relations between values of $A$ and $T_{c}$ of Readman and O'Reilly [1972]. 


\section{Discussion and Conclusions}

Although values of $\mathrm{Z}$ are determined only with great difficulty, lattice parameters and values of $T_{C}$ can be accurately determined for bulk materials. The above discussion of data implies that the improved contour diagrams of lattice parameter (Figure $3 \mathrm{a}$ ) and $\mathrm{T}_{\mathbf{c}}$ (Figure $3 \mathrm{~b}$ ) vs. composition, as plotted in the quadrilateral $\mathrm{Fe}_{2} \mathrm{TiO}_{4}-\mathrm{Fe}_{3} \mathrm{O}_{4}-\mathrm{Fe}_{2} \mathrm{TiO}_{5}-\mathrm{Fe}_{2} \mathrm{O}_{3}$ should provide more accurate correlations among $A, T_{c}$, and $Z$.

The presence of cations other than $\mathrm{Fe}$ and $\mathrm{Ti}$ in titanomagnetite-titanomaghemite may cause significant variations in lattice parameters; values of $T_{c}$ and $Z$ as predicted from the contoured diagram may then be in significant error. However, the amounts of other cations in material occurring in basalts are generally small, $\mathrm{Mn}^{2+}$ and $\mathrm{Al}^{3+}$ being among the most common. The presence of $\mathrm{Mn}^{2+}$ gives rise to an increase in lattice parameter, whereas $\mathrm{Al}^{3+}$ causes a decrease. Lattice parameters equivalent to a spinel phase with composition adjusted to one without minor substituents can easily be calculated assuming linearity [Fukasawa et al., 1993]. Because the effects of cations such as $\mathrm{Mn}^{2+}$ and $\mathrm{Al}^{3+}$ tend to cancel one another, and because the amounts are generally small, their combined effect on lattice parameters is small. For example, we estimate that such cations cause a negligible change of $0.005 \AA$ for the samples of this study. We therefore conclude, as did Ozima et al. [1974], that the presence of small amounts of impurity ions are not the cause of differences in parameters between those of this study and experimental reactants. The general absence of significant proportions of cations such as $\mathrm{Al}^{3+}$ and $\mathrm{Cr}^{3+}$ in magnetic phases in MORB permits those functions to be generally applied. Nevertheless, the contoured functions should be used cautiously where compositions are not directly determined by, e.g., electron microprobe analysis.

Acknowledgments We thank B. Moskowitz and Eric J. Essene who provided helpful comments and P. Solheid who collected Mössbauer data. The manuscript was also substantially improved by further review by Mark J. Dekkers and an anonymous reviewer. Research was supported by National Science Foundation grant EAR 9315913 and a visiting scholarship from the Institute for Rock Magnetism (IRM) for W. X. The IRM is funded by grants from the Keck Foundation and the National Science Foundation and the University of Minnesota.

\section{References:}

Akimoto, S., T. Katsura, and M. Yoshida, Magnetic properties of $\mathrm{TiFe}_{2} \mathrm{O}_{4}-\mathrm{Fe}_{3} \mathrm{O}_{4}$ system and their change with oxidation, $J$. Geomagn. Geoelectr., 9, 165-178, 1957.

Allan, J.E.M., J.M.D. Coey, I.S. Sander, U. Schwertmann, G. Friedrich, and $A$. Wiechowski, An occurrence of a fully-oxidized natural titanomaghemite in basalt, Mineral. Mag. 53, 299-304, 1989.

Beaubouef, R.T. Jr., Three case studies in the application of paleomagnetic and rock magnetic techniques to geologic problems: 1. $15^{\circ} 20^{\prime}$ fracture zone, Atlantic Ocean, 2. Tauride Mountains, southern Turkey, and 3. Port au Port Peninsula, western Newfoundland, Ph. D. thesis, 287 pp., University of Houston, Houston, Texas, 1993.
Collyer, S., N.W. Grimes, D.J. Vaughan, and G. Longworth, Studies of the crystal structure and crystal chemistry of titanomaghemite, Am. Mineral., 73, 153-160, 1988 .

Fukasawa, T., M. Iwatsuki, and M. Furukawa, State analysis and relationship between lattice constants and compositions including minor elements of synthetic magnetite and maghemite, Anal. Chim. Acta, 281, 413-419, 1993.

Hazen, R.M. and L.W. Finger, Comparative Crystal Chemistry, Temperature, Pressure, Composition, and the Variation of Crystal Structure, 231 pp., John Wiley and Sons Ltd., New York, 1982.

Keefer, C.M. and P.N. Shive, Curie temperature and lattice constant reference contours for synthetic titanomaghemites, J. Geophys. Res., 86, 987-998, 1981.

Lindsley, D. H., The crystal chemistry and structure of oxide minerals as exemplified by the Fe-Ti oxides, in Oxide Minerals, 3, edited by D Rumble, pp L1 - L88, Mineralogical Society of America, Reviews in Mineralogy, Washington, 1976.

Moskowitz, B. M., Towards resolving the inconsistencies in characteristic physical properties of synthetic titanomaghemites, Phys. Earth Planet. Inter., 46, 173-183, 1987.

Nishitani, T., and M. Kono, Curie temperature and lattice constant of oxidized titanomagnetite, Geophys. J. R. Astr. Soc., 74, 585-600, 1983.

O'Reilly, W., The identification of titanomagnetite: model mechanisms for the maghemitization and inversion processes and their magnetic consequences, Phys. Earth Planet. Inter., 31, 65-76, 1983.

Ozima, M., and N. Sakamoto, Magnetic properties of synthesized titanomaghemite, J. Geophys. Res., 76, 7035-7046, 1971.

Ozima, M., M. Joshima, and H. Kinoshita, Magnetic properties of submarine basalts and the implications on the structure of the oceanic crust, J. Geomagn. Geoelectr., 26, 335-354, 1974.

Petersen, N., P. Eisenach, U. Bleil, Low temperature alteration of magnetic minerals in ocean floor basalts, in Deep Drilling Results in the Atlantic Ocean: Ocean Crust, edited by M. Talwani, C.G.A Harrison, and D. Hayes, pp. 169-209, American Geophysical Union, Washington, 1979.

Post, J.E., and D.L. Bish, Refinement of crystal structures using powder X-ray diffraction data, in Modern Powder Diffraction, edited by D.L. Bish and J.E. Post, pp. 277-308, Mineralogical Society of America, Reviews in Mineralogy, 20, Washington DC., 1989.

Readman, P.W. and W. O'Reilly, Magnetic properties of oxidized (cation-deficient) titanomagnetites $(\mathrm{Fe}, \mathrm{Ti},[])_{3} \mathrm{O}_{4}, J$. Geomagn. Geoelectr., 24, 69-90, 1972.

Ryall, P.J.C. and J.M. Hall, Iron loss in titanomagnetite during low temperature oxidation, J. Geomagn. Geoelectr., 32, 661-669, 1980.

Ryall, P.J.C. and J.M. Hall, Comment on 'Curie Temperature and Lattice Constant Reference Contours for Synthetic Titanomaghemites' by Charles M. Keefer and Peter N. Shive, J. Geophys. Res., 87, 5391$5392,1982$.

Somboonsuk, $\mathbf{K}$. and $\mathbf{R}$. Trivedi, Dynamical studies of dendritic growth. Acta metall., 33, 1051-1060, 1985.

Waychunas, G.A., Crystal chemistry of oxides and oxyhydroxides, in Oxide Minerals, edited by D.H. Lindsley, pp 11-68, Mineralogical Society of America, Reviews in Mineralogy, 25, Washington DC., 1991.

$\mathrm{Xu}, \mathrm{W}$, Electron microscopic and rock magnetic studies of magnetic minerals in mafic rocks and remagnetized carbonates, $\mathrm{Ph}$. D. thesis, 201 pp., University of Michigan, Ann Arbor, Michigan, 1996.

W. Xu, D. R. Peacor, and R. V. der Voo, Department of Geological Sciences, The University of Michigan, Ann Arbor, MI 48109-1063.

W. A. Dollase, Department of Earth and Space Sciences, UCLA, Los Angeles, CA 90024-1567.

R. Beaubouef, Department of Geosciences, University of Houston, Houston, TX 77204-5503.

(Received November 24, 1995; revised February 25 , 1996; accepted March 7, 1996) 